\title{
FIGURES AND TABLES
}

\section{Figures}

I.1. The Goata family in Paris, ca. 1932

1.1. "The Great Transportation Networks Used by Immigrants in France," 1932

1.2. Foreign labor recruitment, Société générale d'immigration (SGI) pamphlet, 1929

1.3. Foreign laborers signing labor contracts, SGI pamphlet, 1929

1.4. Foreign laborers marrying in France, SGI pamphlet, 192929

3.1. Polish Jew Gendel Mass née Scher, ca. 192275

4.1. League for the Protection of Abandoned Mothers (LPAM) brochure, 1926

4.2. Photograph of officials visiting LPAM offices, 1931

4.3. The office of the League for the Protection of Abandoned Mothers, 1928

5.1. The 11 th arrondissement, 1926

5.2. Romanian Jew Riva Hena Marcu née Matas, ca. 1921

6.1. The marketplace at rue Richard Lenoir, 1922

6.2. Turkish Jew Djoya Abouaf née Baralia and her three children, ca. 1923

7.1. The personnel of the Groupe Amelot, ca. 1940-42

7.2. Serbian Jew Sol Camhi née Colonomos, ca. 1923

7.3. Polish Jew Elsa Handkan née Manachem, ca. 1926

\section{Tables}

1.1. Spanish and Portuguese agricultural workers in France, 1915-18

1.2. Italian agricultural workers in France, 1916-18

1.3. Spanish and Portuguese agricultural workers in France, 1919-22

1.4. Polish agricultural workers in France, 1920-22 
2.1. Marital status of the population of France, 1921

2.2. Marital status of the population of France, 1926

2.3. Marital status of the population of France, 1931

2.4. Marital status of the population of France, 1936

2.5. Naturalized men by marital status in France, 1889-1940

5.1. French and foreign population of Paris residing en garni, 1926 and 1931 